\title{
Evaluation of Changes in Macular Thickness Using Optical Coherence Tomography After Cataract Surgery in Diabetic and Nondiabetic Patients
}

\author{
Özge Pınar Akarsu Açar (D), Ali Olgun² (D), Erdem Ergen² (D), Atila Gökçe Demir² (D), Dilek Güven² (D) \\ ${ }^{1}$ Department of Eye Diseases, Bakırköy Dr Sadi Konuk Training and Research Hospital, İstanbul, Turkey \\ 2Department of Eye Diseases, Şişli Hamidiye Etfal Training and Research Hospital, İstanbul, Turkey
}

Cite this article as: Akarsu Açar ÖP, Olgun A, Ergen E, Demir AG, Güven D. Evaluation of Changes in Macular Thickness Using Optical Coherence Tomography After Cataract Surgery in Diabetic and Nondiabetic Patients. JAREM 2019; 9(1): 32-7.

\begin{abstract}
Objective: To evaluate and compare the changes in central macular thickness (CMT) after uncomplicated phacoemulsification surgery between diabetic and nondiabetic patients using optical coherence tomography (OCT).

Methods: This prospective study included patients who were scheduled for phacoemulsification surgery and intraocular lens (IOL) implantation in the Department of Ophthalmology between November 2012 and February 2013. A total of 28 eyes of 28 patients affected by diabetes mellitus (DM) without preoperative macular edema and 40 eyes of 40 nondiabetic patients having elective phacoemulsification surgery were evaluated. The CMT values were examined using OCT preoperatively and at the postoperative Week 1, Month 1, Month 3, and Month 6 . The duration of DM, antidiabetic medications used, and the presence of mild nonproliferative diabetic retinopathy (NPDR) were also investigated.

Results: The CMT measured by OCT increased significantly in both diabetic and nondiabetic groups after cataract surgery. There was no significant difference between the observed changes of CMT in diabetic and nondiabetic subjects. The correlation between the duration of DM, antidiabetic medications used, the presence of mild NPDR, and CMT changes in diabetics was not significant.

Conclusion: Similar induced CMT changes can be expected in both diabetics with or without mild NPDR and in nondiabetic healthy patients after uncomplicated cataract surgery.

Keywords: Optic coherence tomography, central macular thickness, diabetic retinopathy, cystoid macular edema
\end{abstract}

\section{INTRODUCTION}

Despite all developments in phacoemulsification surgery, cystoid macular edema (CME) is still a common reason of a poor visual outcome of uncomplicated cataract surgery $(1,2)$. Macular edema, which generally affects the outer segments of the retina after uncomplicated phacoemulsification surgery, can be detected in $1 \%$ of all patients with clinical examination (3). However, the incidence of CME rises to $10 \%-20 \%$ when evaluated with fluorescein angiography (FA) or optical coherence tomography $(\mathrm{OCT})(4,5)$. Macular edema is especially common in diabetic patients following cataract surgery (6-8). The level of the preexisting diabetic retinopathy (DR), the presence of clinically significant macular edema (CSME) before the surgery, and duration and regulation of diabetes are all important indicators of postoperative CME. The incidence of CME detected by OCT was reported to be $22 \%$ in the eyes of diabetics after cataract surgery (6). The CSME in the eyes of diabetics showed persistence 12 months after the surgery (9).

Recently, the OCT has become a common, effective, and noninvasive alternative to FA for detecting macular edema (7). With OCT technology, retinal layers can be imaged specifically, and subtle changes in the macular thickness can be detected (8).

In this study, we aimed to assess changes in the macular thickness with OCT after uncomplicated phacoemulsification surgery in diabetic patients without CSME or severe nonproliferative diabetic retinopathy (NPDR) at the time of surgery, and in nondiabetics without any chronic systemic disease. We investigated the association between the CME development and patient charac- 
teristics and treatment in diabetics. We also assessed the effectiveness of OCT in evaluating changes in the macular thickness.

\section{METHODS}

All diabetic and nondiabetic patients older than 18 years who were scheduled for phacoemulsification surgery and intraocular lens (IOL) implantation in the Department of Ophthalmology, Şişli Hamidiye Etfal Training and Research Hospital between November 2012 and February 2013 were screened for inclusion in this prospective nonrandomized study after an approval of the Institutional Review Board. Subjects with a history of uveitis or any other disease that could affect the retinal thickness, prior intraocular surgery such as pars plana vitrectomy or trabeculectomy, mature cataracts that prevented an OCT examination, planned extracapsular cataract extraction, and any systemic disorder that could affect the retinal thickness other than diabetes were excluded from the study. We also excluded patients with Type 1 DM, moderate-to-severe NPDR, proliferative diabetic retinopathy (PDR), or CSME cases at the time of cataract surgery, and those with a history of laser photocoagulation for macular edema. Only one eye of the subjects having bilateral surgery was included in the study. Diabetic patients were assigned to the study group, and the nondiabetics comprised the control group. Subjects underwent phacoemulsification with the IOL insertion, and the results of the two groups were compared.

We conducted this study in accordance with good clinical practices and the ethical principles described in the Declaration of Helsinki. Written informed consent was obtained from all individual participants included in the study.

Preoperatively, information regarding patient characteristics including their age, gender, and duration of diabetes and the antidiabetic medication use was obtained from the subjects, and detailed ophthalmic examinations including best corrected visual acuity (BCVA), the intraocular pressure measurement, biometric testing of axial length and determination of intraocular lens power, slit-lamp biomicroscophy, dilated fundus examination, and optical coherence tomography testing were carried out. An assistant practiced the optical coherence tomography (Optovue RT100 Fourier Domain OCT) testing and measured the maximal retinal thickness (in micrometers) at the center point of the fovea. The MM6 protocol of the Optovue RT100 OCT consists of 12 radial lines each $6 \mathrm{~mm}$ long centred at the fovea to provide 1024 A-scans each. The full retinal thickness is reported at three concentric zones: a circle of $1 \mathrm{~mm}$ diameter centred at the fovea, a parafoveal region that has inner diameter of $1 \mathrm{~mm}$ and outer diameter of $3 \mathrm{~mm}$ and a perifoveal region that has an inner diameter of $3 \mathrm{~mm}$ and outer diameter of $6 \mathrm{~mm}$. We recorded the retinal thickness of $1 \mathrm{~mm}$ diameter centred at the fovea on the thickness map for this study. Preoperatively, we used 1\% tropicamide, $1 \%$ cyclopentolate, and $2.5 \%$ phenylephrine for the pupil dilatation in all patients. No other medication, including nonsteroidal anti-inflammatory drugs, was used for prophylaxis before the surgery. Cataract surgery was performed using the standard phacoemulsification technique under local anesthesia. No complications occurred in any of the cases.

At the postoperative Week 1, we gave the same medication to all patients as topical $1 \%$ prednisolone, $0.3 \%$ ofloxacin, $1 \%$ cy- clopentolate, and $0.3 \%$ tobramycin pomade. The treatment was tapered off over one month in all subjects. All subjects were discharged at the postoperative Day 1 and were called for follow-up at Week 1, Month 1, Month 3, and Month 6.

\section{Statistical Analysis}

The Statistical Package for Social Sciences, version 21.0 (IBM Corp, Armonk, NY, USA) was used for the statistical analysis. Descriptive statistics, including the mean and standard deviation, were calculated for each group. Group comparisons were performed using the Student's t-test and Mann-Whitney U test. A pvalue less than 0.05 was considered to be statistically significant.

\section{RESULTS}

Sixty-eight eyes of 68 patients were included in the study. The study group included 28 eyes of 28 diabetic patients, and the control group included 40 eyes of 40 nondiabetics. There was no statistical difference between the mean age and gender distributions of the diabetic and nondiabetic groups ( $p>0.05)$. Demographic characteristics of the groups and operated eyes are summarized in Table 1.

The center point thickness was normal in all eyes on the preoperative OCT examination. During the postoperative follow-up of both diabetic and control groups, we found the central macular thickness (CMT) values examined by OCT significantly higher than the preoperative values at all intervals (at the postoperative Week 1, Month 1, Month 3, and Month 6) ( $<<0.05)$ (Figure 1).

In diabetic patients, the CMT values at the postoperative Month 1 (mean \pm standard deviation [SD], 249.2 $\pm 64.8 \mu \mathrm{m}$ ) were significantly higher than the CMT values measured at the postoperative Week 1 (mean \pm SD, 225.1 $\pm 22.7 \mu m)(p<0.05)$. There was no significant difference detected between the mean CMT values measured at Month 1 (mean \pm SD, 249.2 $\pm 64.8 \mu \mathrm{m}$ ) and Month 3 (mean $\pm S D, 242.8 \pm 26.8 \mu m)(p>0.05)$ (Figure 1). However, the mean CMT at the postoperative Month 6 (mean \pm SD, $237.7 \pm 26.1 \mu \mathrm{m}$ ) was significantly lower than the mean thickness at the postoperative Month 3 (mean \pm SD, $242.8 \pm 26.8 \mu \mathrm{m})$ $(p<0.05)$ (Table 2).

In the control group, the mean CMT at the postoperative Month 1 (mean \pm SD, 243.1 $\pm 26.6 \mu \mathrm{m}$ ) was significantly higher than the mean thickness at the postoperative Week 1 (mean \pm SD, $229.6 \pm 19.7 \mu \mathrm{m})(\mathrm{p}<0.05)$ like the study group. Also, in accordance with the study group, no significant difference was found between the mean macular thickness at the postoperative Month 1 (mean \pm SD, $243.1 \pm 26.6 \mu \mathrm{m}$ ) and Month 3 (mean \pm SD, 239.7 \pm 18.4 $\mu \mathrm{m})(p>0.05)$ in the control group. But in contrast with the study group, the mean CMT did not change significantly between the

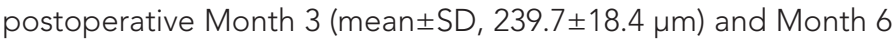
(mean \pm SD, $236.1 \pm 22.3 \mu \mathrm{m})$ in the control group $(p>0.05)$ (Table 2 and Figure 1).

As a result, there was no significant difference between the mean macular thickness values of diabetic and nondiabetic groups at the baseline and the postoperative Week 1, Month 1, Month 3, and Month 6 ( $p>0.05$ for all comparisons) (Table 2). Comparison of the change in the macular thickness measurements did not show any significant difference between consecutive visits ( $p>0.05$ for all comparisons) (Table 2 and Figure 2). 
There was no significant correlation between the CMT and duration of DM ( $p>0.05)$. We also examined the effect of antidiabetic medications on macular thickness by comparing the OAD users with insulin (with or without OAD) users and found no significant difference $(p>0.05)$.

Two eyes from the diabetic group and one eye from the control group with normal findings at the macular examination before surgery developed CME one month after the surgery. No additional treatment was applied, and all three CME cases were reevaluated at the postoperative Month 2 by OCT. The OCT measurement showed that $\mathrm{CME}$ and the intraretinal cysts resolved spontaneously in all patients. OCT results for the CMT of these three cases at the postoperative months 3 and 6 were within the normal limits, and the foveal contours were evaluated as normal without any intraretinal microcystic spaces.

\section{DISCUSSION}

Despite recent surgical and technical progress, CME is still a common cause of low BCVA after cataract surgery. It has been reported that the incidence of $\mathrm{CME}$ after cataract surgery ranges between $0 \%$ and $9 \%(1,10,11)$.

Our study shows that the CMT increases after standard phacoemulsification surgery in both diabetic and nondiabetic patients, and that the increase from the baseline is the highest at the postoperative Month 1, decreasing gradually afterwards.

\section{Table 1. Patient characteristics}

\begin{tabular}{|c|c|c|c|c|c|c|}
\hline & & \multicolumn{2}{|c|}{ Diabetic } & \multicolumn{2}{|c|}{ Nondiabetic } & \multirow[b]{2}{*}{$p$} \\
\hline & & Mean \pm SD & Median(Min-Max) & Mean \pm SD & Median(Min-Max) & \\
\hline Age & & $64.6 \pm 11.2$ & $67 \quad 28-76$ & $65.9 \pm 8.9$ & $6743-80$ & $0.599 * *$ \\
\hline Gender & Female & $14 \quad 50.0 \%$ & & $2255.0 \%$ & & $0.684^{\star *}$ \\
\hline Eye & Right & $16 \quad 57.1 \%$ & & $1947.5 \%$ & & $0.484^{\star}$ \\
\hline Antidiabetic & None & $310.7 \%$ & & & & \\
\hline \multirow[t]{3}{*}{ Treatment } & Insulin & $5 \quad 17.9 \%$ & & & & \\
\hline & OAD & $18 \quad 64.3 \%$ & & & & \\
\hline & OAD+Insulin & $27.1 \%$ & & & & \\
\hline \multirow[t]{2}{*}{ Fundus } & Normal & $19 \quad 67.9 \%$ & & & & \\
\hline & Mild NPDR & $932.1 \%$ & & & & \\
\hline Duration of $\mathrm{D}$ & ars) $9.3 \pm 9.6$ & $60-40$ & & & & \\
\hline
\end{tabular}

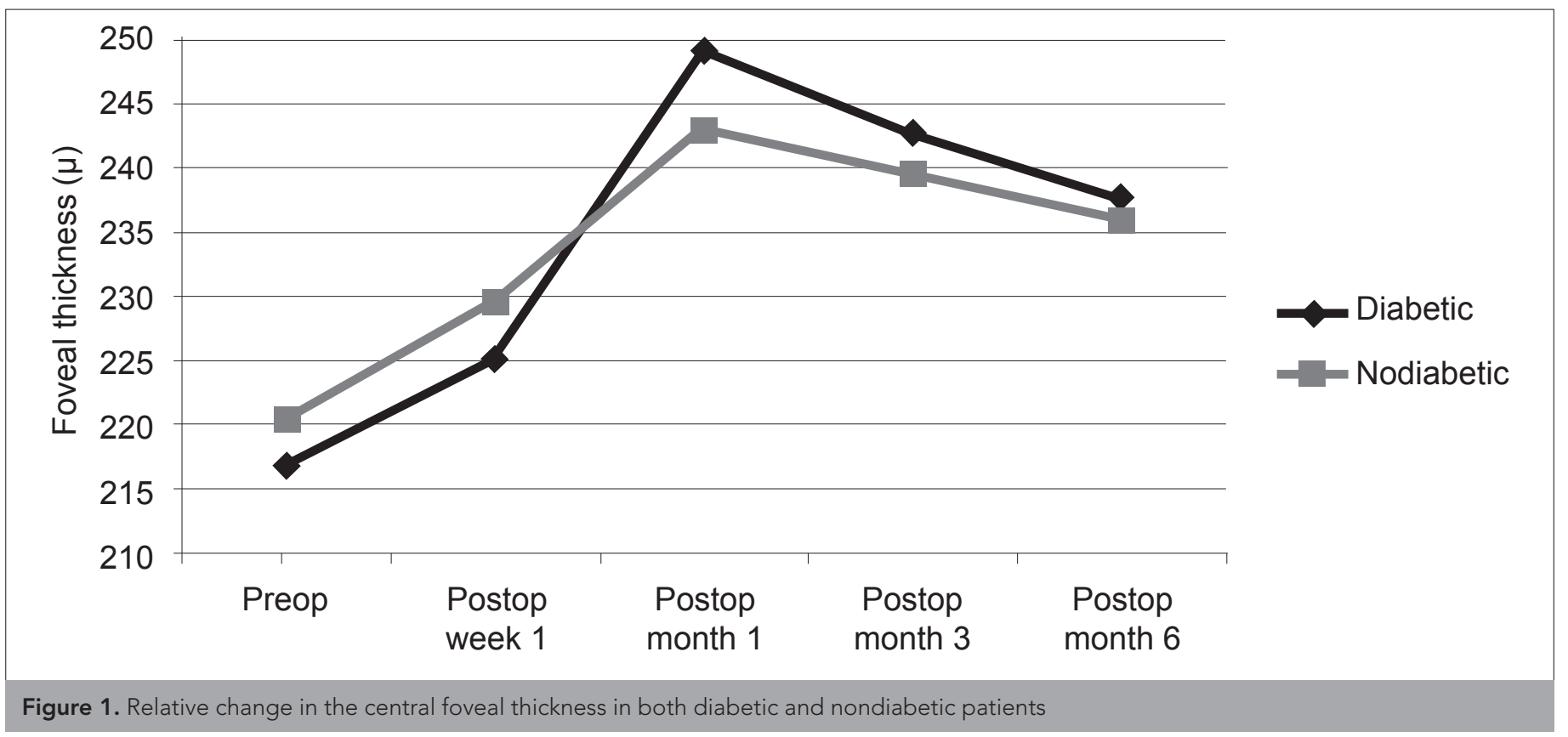


Different definitions have been proposed for CME. Ching et al. (12) defined postoperative CME as the appearance of cystic changes and an increase in the retinal thickness indicated by OCT. Kim et al. (6) suggested an increase in the CMT greater than $30 \%$ (or at least $50 \mu \mathrm{m}$ ) for CME after phacoemulsification surgery (12), and Sanchez-Tocino et al. (13) defined postoperative CME as an increase of at least three standard deviations in CMT.
We defined postoperative CME as an increase greater than 30\% in CMT compared to the preoperative level and the presence of intraretinal cysts detected by OCT.

It is often stated that the increase in CMT after cataract surgery reaches the maximum values at the postoperative first or second month. After the postoperative third month, a progressive de-

Table 2. Comparison of the changes in central macular thickness (CMT) between the groups

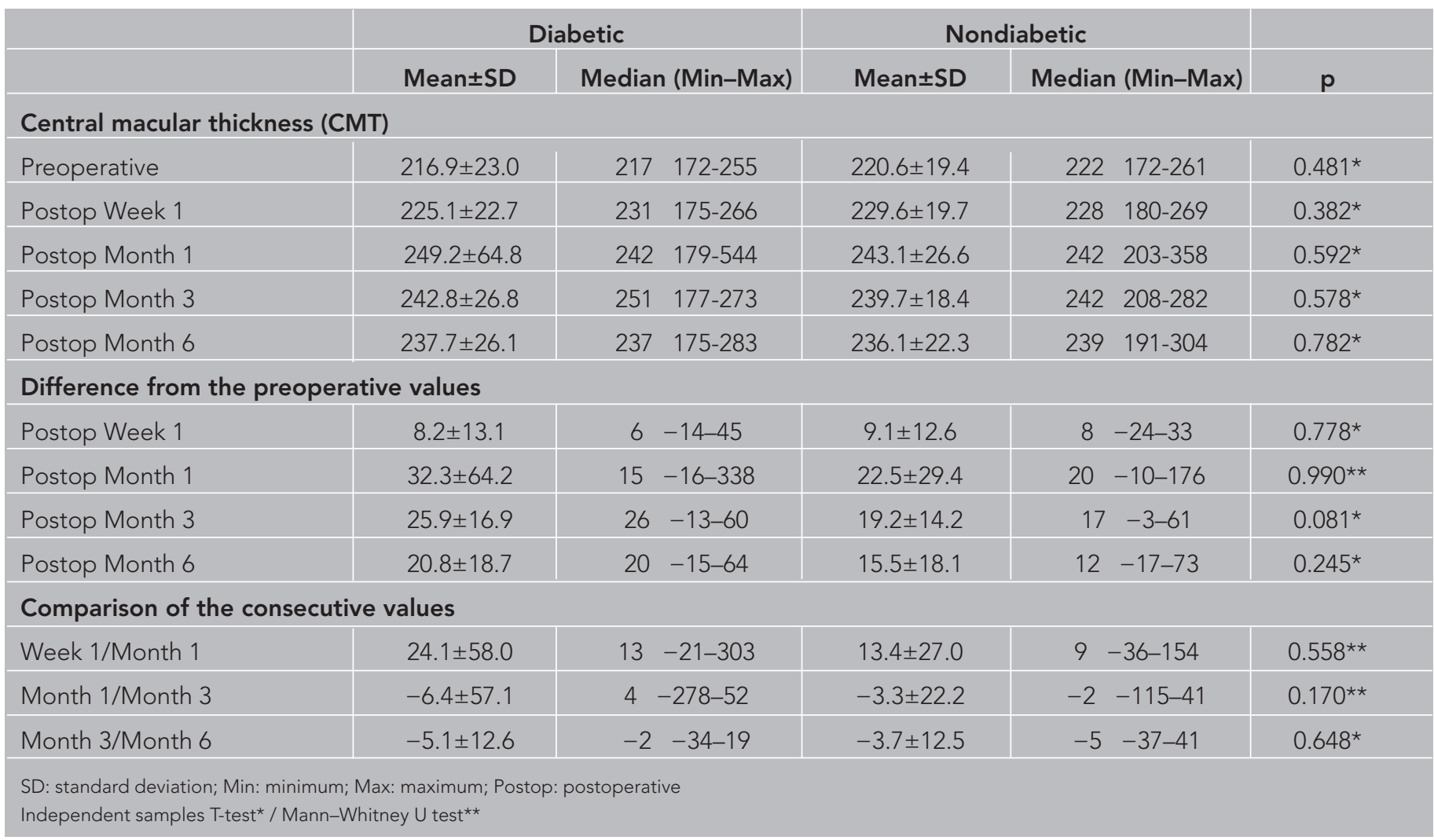

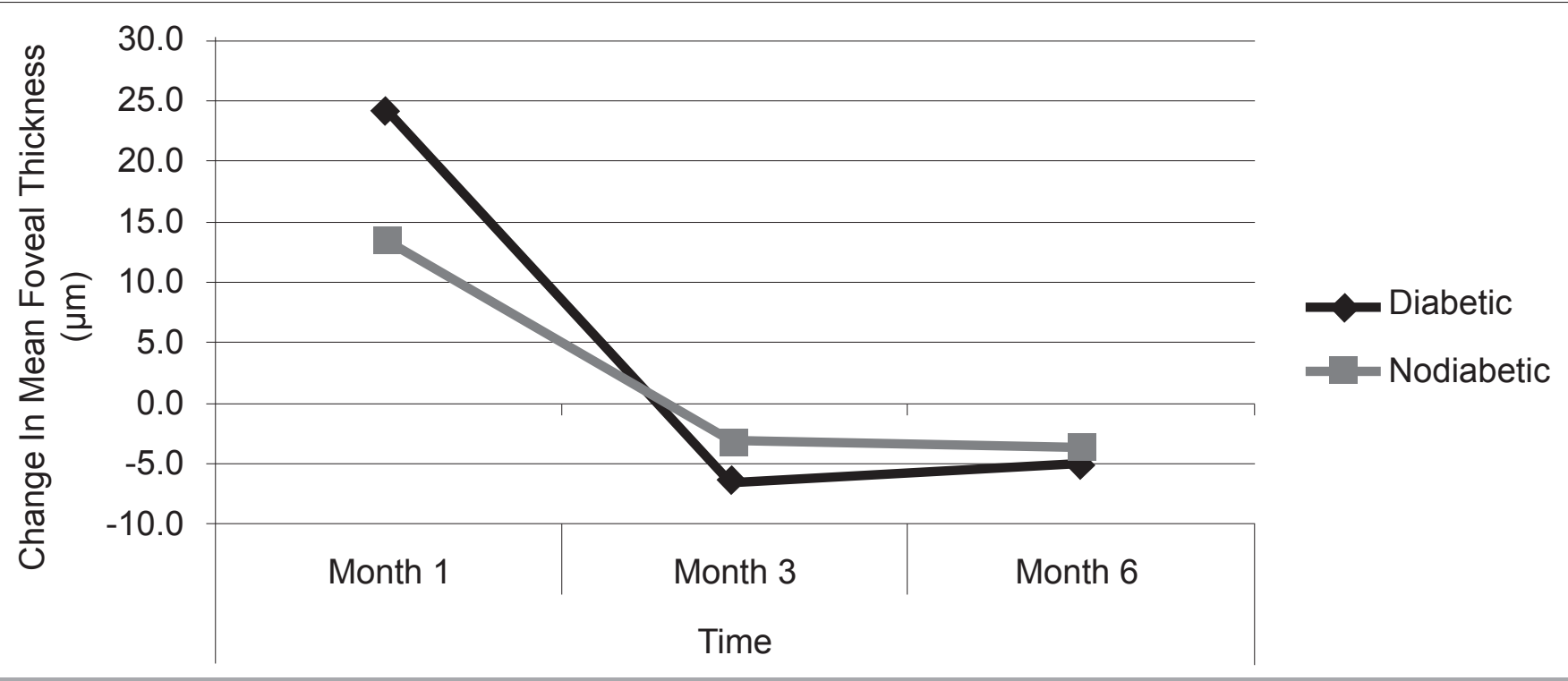

Figure 2. Mean change in the central foveal thickness on consecutive visits. Month 1 value represents the mean foveal thickness at the third month visit minus the mean measurement at the first week. Month 3 value is the difference between Month 3 and Month 1, and Month 6 value is the difference between Month 6 and Month 3 
crease begins in the CMT until it reduces back to the preoperative values around the postoperative Month 6 (14-16). We found the maximum increase in the postoperative CMT of 40 nondiabetic subjects at the postoperative Month 1 by OCT (Figure 1). We also detected CME in one subject in the nondiabetic group at the postoperative Month 1 .

Macular edema in diabetics with DR can be an important reason of low BCVA after cataract surgery $(17,18)$. CME after cataract surgery in diabetic patients may be caused by the surgical practice (Irvine-Gass Syndrome) or only having DM could be the cause of CME. Most of CME cases detected after cataract surgery resolve spontaneously within 6 months, but DME resists to resolve $(6,19,20)$. Therefore, laser therapy for macular edema could be delayed until 6 months after surgery $(19,20)$. Dowler et al. (9) reported that the CSME in patients with mild DR commonly resolved after cataract surgery (20).

In our study, two eyes in the diabetic group without apparent macular edema or DR before surgery developed CME at the postoperative Month 1. No additional treatment was applied, and the OCT examination at the postoperative Month 2 showed that $\mathrm{CME}$ and the intraretinal cysts resolved spontaneously in both subjects.

Kim et al. (6) suggested that there was an association between the level of DR and central retinal thickening. The increase in the central retinal thickness in subjects with moderate or severe NPDR or PDR was much higher than in the patients without DR. Insulin use for the regulation of DM, a history of diabetes longer than 10 years, a history of focal photocoagulation for CSME and DR levels were all correlated with an increased central retinal thickening at Month 1 and Month 3. Hayashi et al. (21) reported an increase in the CMT after cataract surgery in both diabetic patients with or without DR. The increase from the baseline was maximum at the postoperative Month 3 and was greater in eyes affected by DR. However, this study could not detect a relationship between the duration of DM, OAD or insulin use, hypertension or nephropathy, and the degree of macular edema. In another study, the change in the CMT was examined for 6 months in 26 diabetic subjects without preoperative DR and in 60 nondiabetics, and there was no significant difference detected between the groups. This study also reported that the duration of DM and the antidiabetic medication application were not associated with the CMT after cataract surgery (14). Similarly, we found no significant correlation between the duration of DM or antidiabetic medication application and the change in CMT. It is also stated in the literature that topical nonsteroidal anti-inflammatory drugs (NSAIDs) can also be used after cataract surgery to prevent the development of CME, especially in diabetic eyes $(16,20,22)$. The multicenter and randomized study by Singh et al. (23) including 263 adult diabetic patients with NPDR undergoing cataract surgery reported that adding a topical NSAID to a standard steroid medication after uncomplicated surgery helps to prevent the development of postoperative CME. Intraoperative triamcinolone acetonide or anti-vascular endothelial growth factor (anti-VEGF) injections have also been suggested for diabetics with CSME or a history of focal photocoagulation for $\operatorname{CSME}(6,20)$. The Early Treatment Diabetic Retinopathy Study recommends considering photocoagulation before cataract surgery in patients with severe
NPDR or CSME, which may provide relatively good visual reports $(24,25)$.

Previous studies considered FA as the gold standard for diagnosing subclinical CME following cataract surgery $(11,26)$. The incidence of subclinical CME diagnosed by this method was reported to range between $9.1 \%$ and $25.5 \%(1,11,26)$. Nevertheless, the invasive nature of this method renders it impractical, as well as ethically questionable to be performed on all postoperative cataract patients. In addition, FA can detect the retinal vascular leakage, but it cannot quantify the retinal thickening in postoperative CME (16). As an alternative to FA, non-invasive retinal imaging with OCT may be equally effective at detecting the $\mathrm{CME}$, and it offers the ability to quantify and repeat the results over time (16).

In this study, we accepted OCT as an effective, non-invasive, and useful diagnostic tool in determining CME and CMT in patients undergoing uncomplicated cataract surgery.

\section{Study Limitations}

The number of subjects in this study was insufficient to evaluate the effect of mild NPDR in CMT. Further studies designed to investigate the effect of NPDR on macular thickness in larger groups are necessary to analyze this relationship.

\section{CONCLUSION}

We have demonstrated a significant increase in CMT after uncomplicated cataract surgery measured by OCT, both in diabetic subjects with or without mild NPDR and in nondiabetics. The increase in the CMT after the cataract surgery reached maximum in both groups during the first month. We found no significant difference in the CMT increase between diabetic and healthy patients. We found no significant correlation between the duration of DM, antidiabetic medication, or the presence of mild NPDR and CMT changes in diabetics. The difference in CMT between the subjects with mild NPDR and without DR was not significant either.

Ethics Committee Approval: Authors declared that the research was conducted according to the principles of the World Medical Association Declaration of Helsinki "Ethical Principles for Medical Research Involving Human Subjects", (amended in October 2013).

Informed Consent: Written informed consent was obtained from the patients included in the study.

Peer-review: Externally peer-reviewed.

Author Contributions: Concept - Ö.P.A.; Design - Ö.P.A.; Supervision - D.G.; Resources - D.G., E.E., A.G.D.; Data Collection and/or Processing - Ö.P.A., E.E., A.G.D.; Analysis and/or Interpretation - Ö.P.A., D.G.; Literature Search - Ö.P.A.; Writing Manuscript - Ö.P.A., A.O.; Critical Review - A.O., D.G., A.G.D.

Conflict of Interest: The authors have no conflict of interest to declare.

Financial Disclosure: The authors declared that this study has received no financial support.

\section{REFERENCES}

1. Mentes J, Erakgun T, Afrashi F, Kerci G. Incidence of cystoid macular edema after uncomplicated phacoemulsification. Ophthalmologica 2003; 217: 408-12. [CrossRef]

2. Francois $\mathrm{J}$, Verbraeken $\mathrm{H}$. Complications in 1.000 consecutive intracapsular cataract extractions. Ophthalmologica 1980; 180: 121-8. [CrossRef] 
3. Quillen DA, Blodi BA, Bennett TJ. Clinical Features of Retinal Disease. In: Clinical Retina. ed. AMA Press 2002:41-70.

4. Fu A, Ahmed I, Al E. Cystoid Macular Edema. In: Yanoff M, Duker JS ed Ophthalmology St. Lois, Mosby Inc, 2004: 956-62.

5. Gucukoglu A. Komplikasyonlar. In: Fakoemulsifikasyon Turk Oftalmoloji Dernegi Egitim Yayınları No: 2 Bursa, Fikret Ozsan Matbaası; 2004: 213-223.

6. Kim SJ, Equi R, Bressler NM. Analysis of macular edema after cataract surgery in patients with diabetes using optical coherence tomography. Ophthalmology 2007; 114: 881-9. [CrossRef]

7. Von Jagow B, Ohrloff C, Kohnen T. Macular thickness after uneventful cataract surgery determined by optical coherence tomography. Graefes Arch Clin Exp Ophthalmol 2007; 245: 1765-71. [CrossRef]

8. Biro Z, Balla Z, Kovacs B. Change of foveal and perifoveal thickness measured by OCT after phacoemulsification and IOL implantation. Eye 2008; 22: 8-12. [CrossRef]

9. Dowler JG, Sehmi KS, Hykin PG, Hamilton AM. The natural history of macular edema after cataract surgery in diabetes. Ophthalmology 1999; 106: 663-8. [CrossRef]

10. Nicholas S, Riley A, Patel H, Neveldson B, Purdie G, Wells AP. Correlations between optical coherence tomography measurement of macular thickness and visual acuity after cataract extraction. Clin Exp Ophthalmol 2006; 34: 124-9. [CrossRef]

11. Gulkilik G, Kocabora S, Taskapili M, Engin G. Cystoid macular edema after phacoemulsification: risk factors and effect on visual acuity. Can J Ophthalmol 2006; 41: 699-703. [CrossRef]

12. Ching H, Wong A, Wong C, Woo D, Chan C. Cystoid macular oedema and changes in retinal thickness after phacoemulsification with optical coherence tomography. Eye 2006; 20: 297-303. [CrossRef]

13. Sanchez-Tocino $H$, Alvarez-Vidal A, Maldonado M, Moreno-Montanes J, Garcia-Layana A. Retinal thickness study with optical coherence tomography in patients with diabetes. Invest Ophthalmol Vis Sci 2001; 25: 1492-7.

14. Jurecka T, Batkova Z, Ventruba J. Macular edema after an uncomplicated cataract surgery. Cesk Slov Oftalmol 2007; 63: 262-73.

15. Cagini C, Fiore T, laccheri B, Piccinelli F, Ricci MA, Fruttini D. Macular thickness measured by optical coherence tomography in a healthy population before and after uncomplicated cataract phacoemulsification surgery. Curr Eye Res 2009; 34: 1036-41. [CrossRef]

16. Vukicevic M, Gin T, Al-Qureshi S. Prevalence of optical coherence tomography diagnosed postoperative cystoid macular oedema in patients following uncomplicated phaco-emulsification cataract surgery. Clin Experiment Ophthalmol 2012; 40: 282-7. [CrossRef]

17. Nelson ML, Martidis A. Managing cystoid macular edema after cataract surgery. Curr Opin Ophthalmol 2003; 14: 39-43. [CrossRef]

18. Krepler K, Biowski R, Schrey S, Jandrasits K, Wedrich A. Cataract surgery in patients with diabetic retinopathy: visual outcome, progression of diabetic retinopathy and incidence of diabetic macular edema. Graefes Arch Clin Exp Ophthalmol 2002; 240: 735-8. [CrossRef]

19. Benson WE. Cataract surgery and diabetic retinopathy. Curr Opin Ophthalmol 1992; 3: 396-400. [CrossRef]

20. Kwon SI, Hwang DJ, Seo JY, Park IW. Evaluation of changes of macular thickness in diabetic retinopathy after cataract surgery. Korean $J$ Ophthalmol 2011; 25: 238-42. [CrossRef]

21. Hayashi $\mathrm{K}$, Igarashi $\mathrm{C}$, Hirata $\mathrm{A}$, Hayashi $\mathrm{H}$. Changes in diabetic macular oedema after phacoemulsification surgery. Eye 2009; 23: 389-96. [CrossRef]

22. Sahin M, Cingu AK, Gozum N. Evaluation of cystoid macular edema using optical coherence tomography and fundus autofluorescence after uncomplicated phacoemulsification surgery. J Ophthalmol 2013; 2013: 376013. [CrossRef]

23. Singh R, Alpern L, Jaffe GJ, Lehmann RP, Lim J, Reiser HJ, et al. Evaluation of nepafenac in prevention of macular edema following cataract surgery in patients with diabetic retinopathy. Clin Ophthalmol 2012; 6: 1259-69. [CrossRef]

24. Early Treatment Diabetic Retinopathy Study research group. Photocoagulation for diabetic macular edema. Early Treatment Diabetic Retinopathy Study report number 1. Arch Ophthalmol 1985; 103: 1796-806. [CrossRef]

25. Pollack A, Leiba H, Bukelman A, Oliver M. Cystoid macular edema following cataract extraction in patients with diabetes. Br J Ophthalmol 1992; 76: 221-4. [CrossRef]

26. Ursell P, Spalton D, Whitcup S, Nussenblatt R. Cystoid macular edema after phacoemulsification: relationship to blood-aqueous barrier damage and visual acuity. J Cataract Refract Surg 1999; 25: 1492-7. [CrossRef] 